\title{
MANGGALI
}

Jurnal Pengabdian dan Pemberdayaan Masyarakat http://e-journal.ivet.ac.id/index.php/manggali

\section{Penyuluhan dan Bimbingan Teknik Pengawas TPS Kampanye Pemilu Tingkat Desa dalam Pemilihan Bupati dan Wakil Bupati Tahun 2020 se-Kecamatan Mranggen Kabupaten Demak}

\author{
Tugino $^{1}$, Harini $^{2},{ }^{*}$ Slamet $^{3}$ \\ 1,2,3 Universitas Ivet \\ * $\underline{\text { slamet.doktor@gmail.com }}$
}

DOI: $\underline{\text { https://doi.org/10.31331/manggali.v1i1.1544 }}$

\section{Info Articles}

Sejarah Artikel:

Disubmit : November 2020

Direvisi : Desember 2020

Disetujui : Januari 2021

Keywords:

TPS Supervisor, Election, Regent and Deputy

\begin{abstract}
Abstrak
Pengabdian pada masyarakat berupa Penyuluhan dan Bimbingan Teknis Calon Pengawas Desa pada Pemilihan Bupati dan wakil Bupati Demak di tingkat Desa tahun 2020 se-Kecamatan Mranggen bertempat di Pendopo Kecamatan Mranggen dengan metode bimbingan teknis dan penyuluhan tentang kepemiluan, khususnya pemilihan kepala daerah. Kegiatan ini meliputi pemaparan tentang kepemiluan, Sumber Daya Manusia (SDM) Pemilihan Umum (Pemilu), pengawasan partisipatif, dan bimbingan tekknis tentang kepengawasan Pemilu khususnya bagi calon-calon pengawas Pemilu.

Pengabdian ini terlaksana dengan baik berkat kerjasama beberapa instansi, yaitu pihak Kecamatan Mranggen, Bawaslu Kabupaten, Demak Panitia Pengawas Kecamatan (Panwaslucam) dan Desa Mranggen termasuk Lembaga Penelitian dan Pengabdian pada Masyarakat (LPPM) Universitas Ivet yang juga memberikan kontribusi dan segala administrasinya demi kelancaran dalam pelaksanaan kegiatan Penyuluhan Pengawas Tempat Pemungutan Suara (TPS) kepemiluan .

Kegiatan penyuluhan dan bimbingan teknis mengambil judul: "Penyuluhan dan Bimbingan Teknis Pengawas TPS Pemilu Desa pada Pemilihan Bupati dan wakil Bupati Demak Tahun 2020 se-Kecamatan Mranggen Kabupaten Demnak" sangat terkait dengan beberapa mata kuliah dan dalam pembelajaran Pendidikan Kewarganegaraan pada seluruh Fakultas di Universitas Ivet yang bermanfaat bagi mahasiswa dan taruna, yang dalam kehidupan bermasyarakat, berbangsa, dan bernegara sering ditunjuk sebagai penyelenggara Pemilu dapat mengetahui tentang peraturan pelaksanaan kepemiluan, utamanya terkait dengan kepengawasan Pemilu Kepala Daerah.
\end{abstract}




\begin{tabular}{l} 
Committee (Panwaslucam) and Mranggen Village including the Ivet University \\
Research and Community Service Institute (LPPM) which also contributed and all \\
its administration for the smooth running of implementation of electoral polling \\
station supervisors (TPS) outreach activities. \\
The extension and technical guidance activities take the title: "Counseling and \\
Technical Guidance for Village Election TPS Supervisors in the 2020 Election of \\
the Regent and Deputy Regent of Demak in Mranggen District, Demnak Regency" \\
is closely related to several courses and in learning Citizenship Education in all \\
Faculties at Ivet University. which is useful for students and cadets, who in the life \\
of the community, nation and state are often appointed as election organizers, can \\
find out about electoral implementation regulations, especially those related to the \\
supervision of the Regional Head Election. \\
Keywords: TPS Supervisor, Election, Regent and Deputy. \\
\hline E-maila slamet.doktor@gmail.com
\end{tabular}




\section{PENDAHULUAN}

Kecamatan Mranggen adalah salah satu Kecamatan di Kabupaten Demak Provinsi Jawa Tengah terdapat 19 Desa dengan karakteristik pedesaan dengan luas wilayah $72,22 \mathrm{Km}^{2}$, sedangkan jumlah penduduk per April 2020 dan kepadatannya menyampai 2,181,44 jiwa (Data Statistik Kecmatan Mranggen, 2020). Secara visualisasi letak Kecamatan Mranggen Kabupaten Demak dapat ditampilkan pada gambar berikut.

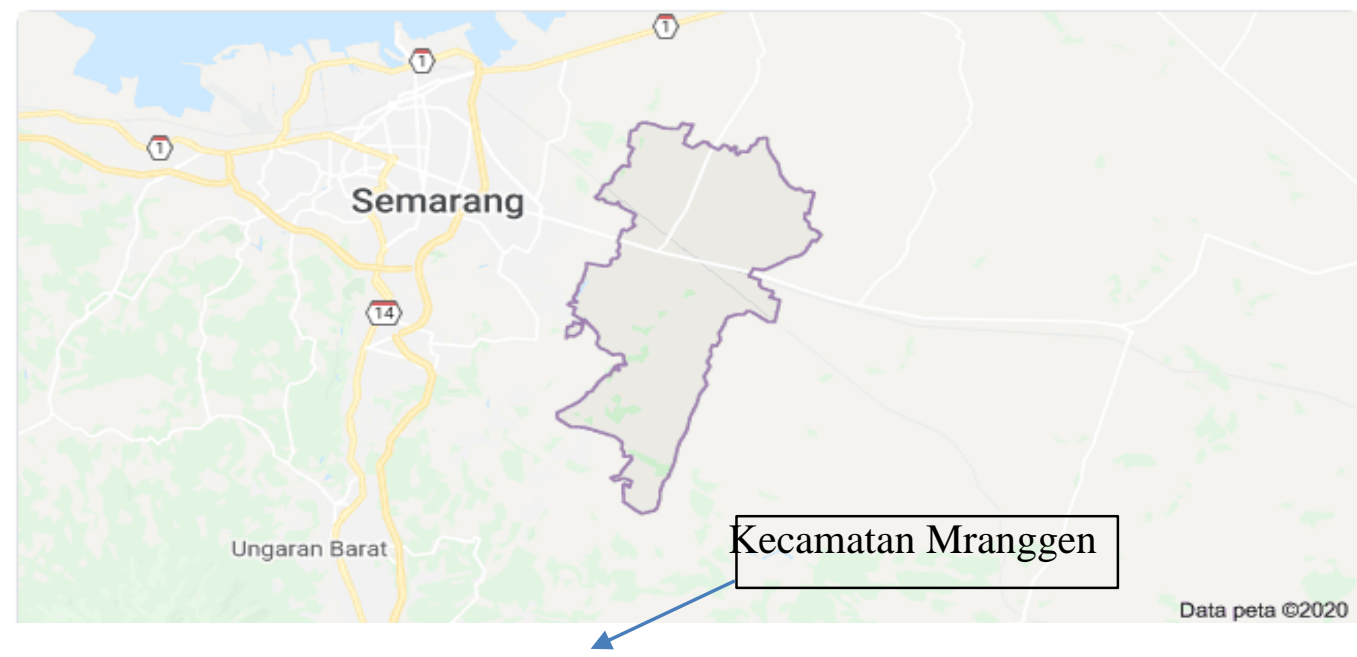

\section{Gambar: Letak Kecamatan Mranggen}

Indonesia dalam penyelanggaraan Pemilu sejak tahun 1995, 1971, dan 1977, belum ada lembaga pengawasan Pemilu. Lembaga pengurus Pemilu baru muncul pada tahun 1992, hal iti salah satunya disebabkan oleh adanya pelanggaran dan manipulasi perhitungan suara yang dilakuakan oleh petugas Pemilu pada tahun 1971. Dengan pelanggaran dan kecurangan pemilu yang dilaksanakan pada tahun 1977 yang jauh lebih masif, protes-protes yang dilontarkan pada elite politik sehingga muncul gagasan bersama Pemerintah dan setuju untuk mendapatkan wakil penyelenggara Pemilu ke dalam kepanitian Pemilu. Sampai pada saat ini perubahan demi perubahan undangundang Pemilu, yaitu Undang-Undang Nomor 10 Tahun 2016 tentang Perubahan Kedua Atas Undang-Undang Nomor 1 Tahun 2015 tentang Penetapan Peraturan Pemerintah Pengganti Undang-Undang Nomor 1 Tahun 2014 tentang Pemilihan Gubernur, Bupati dan Wali Kota menjadi Undang-Undang yang sampai sekarang digunakan adalah Undang-Undang Nomor 10 Tahun 2016.

Selain itu Pemerintah juga mengintroduksi adanya badan baru yang terlibat dalam urusan Pemilu untuk mendampingi komisi Pemilihan Umum, yaitu badan baru yang 
Penyuluhan dan Bimbingan Teknik Pengawas TPS Kampanye Pemilu Tingkat Desa dalam Pemilihan Bupati dan Wakil Bupati Tahun 2020 se-Kecamatan Mranggen Kabupaten Demak

bernama Badan Pengawas Pemilihan Umum yang bertugas mengawasi pelaksanaan pemilihan umum, yang sampai sekarang keberadaan Badan Pengawas Pemilu (BAWASLU) tersebut masih eksis.

Melalui struktur fungsi dan mekanisme kerja yang baru, pengawas Pemilu tetap diaktifkan untuk Pemilu 1999, namanya pun diubah dari panitia Pengawas Pelaksanaan Pemilihan Umum (Panwaslu) baik dari tingkat desa sampai tingkat pusat. Namun seiring dengan perkembangan zaman dan semakin kompleknya persoalan sampai tingkat desa, maka dibentuklah Panitia Pengawas Pemilu Lapangan (PPl) di tingkat desa. Rasio berdasarkan Tempat Pemungutan Suara (TPS) yaitu antara 1 samapai 20 TPS diawasi oleh 1 (satu) Pengawas Pemilu Lapangan (PPL) dan dari 21 sampai 30 diawasi 2 PPL dan 31 sampai 50 TPS diawasi 3 PPL, antara 50 lebih diawasi 5 PPL dan seterusnya, khusus untuk tingkat Kecamatan Mranggen jumlah seluruhnya dari 19 Desa mencapai 57 Panitia Pengawas Lapangan (PPL). Dengan demikian dari Pengawas Lapangan yang cukup banyak tersebut tentu ada sebagian Pengawas Lapangan yang belum begitu paham tentang fungsi dan perannya sebagai paniti Pengawas Lapangan di tingkat desa masing-masing, hal tersebut dapat terjadi yang ditengarai disebabkan oleh faktor pendidikan, faktor pemahaman penyelenggaraan Pemilu kurang, dan faktor lingkungan. Dengan melihat jumlah Panitia Pengawas Pemilu Lapangan yang cukup banyak tersebut, khususnya di wilayah Kecamatan Mranggen Kabupaten Demak, maka sebagai bentuk dharma dari seorang dosen, salah satunya adalah pengabdian pada masyarakat (selain tugas pendidikan/pengajaran dan penelitian), tim pengabdian memiliki gagasan dan memandang perlu untuk dilakukan bimbingan teknis agar person-person yang berkecimpung dalam pelaksanaan kepanitiaan Pemilu Serentak yang dilaksanakan pada hari Rabu, 9 Desember 2020 tersebut dapat melaksanakan tugasnya dengan baik dan lancar. Adapun bentuk pengabdian pada masyarakat terkait dengan penyuluhan dan bimbingan teknis Pengawas TPS pada kampanye Pemilu Tingkat Desa dalam Pemilihan Bupati dan wakil Bupati tahun 2020 se-Kecamatan Mranggen Kabupaten Demak. Dengan demikian tujuan dari pelaksanaan kegiatan pengabdian pada masyarakat ini adalah: 1) memberikan pemahaman peraturan-peraturan atau undang-undang tentang penyelenggaraan Pemilu pada pemilihan Bupati dan wakil Bupati Demak; 2) memberikan pemahaman tentang tugas dan wewenang sebagai Pengawas Pemilu Desa (PPD) di tingkat desa atau kelurahan; dan 3) memberikan informasi dan penjelasan 
MANGGALI - https://doi.org/10.31331/manggali.v1i1.1544/

Tugino, Harini, Slamet

tentang strategi Pengawasan Pemilihan Umum Bupati dan wakil Bupati di wilayah seluruh desa se-Kecamatan Mranggen Kabupaten Demak.

\section{METODE}

\section{Tempat Kegiatan}

Tempat pelaksanaan kegiatan di Pendopo Kantor Kecamatan Mranggen Kabupaten Demak, Jalan Raya Nomor 172 Mranggen Kabupaten Demak.

\section{Waktu Kegiatan}

Kegiatan dilaksanakan mulai tanggal 4 Oktober-30 Desember 2020 yang bersifat kesinambungan. Penyuluhan dan pelaksanaan bimbingan teknis dilaksanakan pada setiap hari Sabtu pada sore hingga malam hari. Kegiatan ini diharapkan tidak hanya sekali pada kegiatan Pilkada Serentak Rabu, 9 Desember 2020, tetapi dapat berlanjut yang tidak hanya terbatas pada pesta demokrasi saja namun dapat dilaksanakan pada waktu-waktu berikutnya agar lebih mendalam dalam pemahaman materi tentang peraturan-peraturan terkait dengan penyelenggaraan kepemiluan.

\section{Lingkup/Cakupan Kegiatan}

1) Perlunya Partisipasi Masyarakat dalam Pemilu 2020 tentang Pilkada (Bupati dan Wakil) Kabupaten Demak, oleh Camat Mranggen sebagai pemangku wilayah.

2) Pemaparan materi 1 tentang Penyuluhan dan bimbingan Teknis oleh Ketua tim pengabdian.

3) Pemaparan materi 2 tentang Pentingnya Sumber Daya Manusia (SDM) dan Organisiasi.

4) Pemaparan Materi 3 tentang Perlunya Partsipasi Masyarakat sebagai Potensi Masalah dalam Pemilihan Kepala Daerah.

\section{HASIL DAN PEMBAHASAN}

\section{Hasil}

Kegiatan pengabdian pada masyarakat yang dilaksanakan di Pendopo Kantor Kecamatan Mranggen Kabupoaten Demak ini melalui tahapan berikut.

1. Persiapan kegiatan pemaparan di kantor kecamatan

1) Materi bimbigan teknis dengan pembuatan PPT untuk penyampaian materi. 
2) Sarana kegiatan (projector/LCD, pengeras suara, alat tulis, dan sarana pendukung lainnya).

3) Persiapan laporan hasil pengabdian.

2. Persiapan kegiatan/pelaksanaan

1) Persiapan peralatan yang digunakan untuk bimbingan teknis ceramah.

2) Persiapan bahan dan materi yang harus digunakan sesuai jadwal.

Kegiatan pengabdian dilakukan dalam jangka waktu 4 x 5 jam pada hari Sabtu dalam bulan Desember 2020 dengan jadwal sebagai berikut.

\section{Hari Pertama}

\begin{tabular}{|c|c|l|l|}
\hline No & \multicolumn{1}{|c|}{ Waktu } & \multicolumn{1}{|c|}{ Kegiatan } & \multicolumn{1}{|c|}{ Penyaji } \\
\hline 1. & $18.00-19.00$ & Sambutan Ketua DPM & Tugino, SH. MH. \\
\hline 2. & $19.00-19.30$ & Sambutan Pemangku Wilayah & Camat Mranggen \\
\hline 3. & $19.30-20.00$ & $\begin{array}{l}\text { Materi 1 Penyuluhan dan } \\
\text { Bimbingan Teknis Pengawas } \\
\text { Pemilu Desa Pemilihan Bupati } \\
\text { dan Wakil Bupati Demak }\end{array}$ & Tugino, SH., MH. \\
\hline 4. & $20.00-20.30$ & $\begin{array}{l}\text { Materi 2 SDM (Sumber Daya } \\
\text { Manusia) }\end{array}$ & Harini, SE, MM. \\
\hline 5. & $20.30-21.00$ & $\begin{array}{l}\text { Materi 3 Pengawasan Partisipatif } \\
\text { Dr. Slamet, S,Pd, } \\
\text { M.Pd, M.Si. }\end{array}$ \\
\hline 6. & $21.00-21.30$ & Istirahat atau Penutup & \\
\hline
\end{tabular}

\section{Hari Kedua}

\begin{tabular}{|c|c|l|l|}
\hline No & Waktu & \multicolumn{1}{|c|}{ Kegiatan } & Penyaji \\
\hline 1. & $18.00-19.00$ & Sambutan Ketua DPM & Tugino, SH. MH \\
\hline 2. & $19.00-19.30$ & Sambutan Pemangku Wilayah & Camat Mranggen \\
\hline 3. & $19.30-20.00$ & $\begin{array}{l}\text { Materi 1 Penyuluhan dan } \\
\text { Bimbingan Teknis Pengawas } \\
\text { Pemilu Desa Pemilihan Bupati }\end{array}$ & Tugino, SH. MH \\
\hline
\end{tabular}




\begin{tabular}{|c|l|l|l|}
\hline & & dan Wakil Bupati Demak & \\
\hline 4. & $20.00-20.30$ & $\begin{array}{l}\text { Materi 2 SDM (Sumber Daya } \\
\text { Manusia) }\end{array}$ & Harini SE, MM \\
\hline 5. & $20.30-21.00$ & Materi 3 Pengawasan Partisipatif & $\begin{array}{l}\text { Dr . Slamet, S.Pd, } \\
\text { M.Pd, M.Si. }\end{array}$ \\
\hline 6. & $21.00-21.30$ & Istirahat atau Penutup & \\
\hline
\end{tabular}

\section{Hari Ketiga}

\begin{tabular}{|c|c|l|l|}
\hline No & \multicolumn{1}{|c|}{ Waktu } & \multicolumn{1}{|c|}{ Kegiatan } & \multicolumn{1}{|c|}{ Penyaji } \\
\hline 1. & $18.00-19.00$ & Sambutan Ketua DPM & Tugino, SH. MH \\
\hline 2. & $19.00-19.30$ & Sambutan Pemangku Wilayah & Camat Mranggen \\
\hline 3. & $19.30-20.00$ & $\begin{array}{l}\text { Materi 1 Penyuluhan dan } \\
\text { Bimbingan Teknis Pengawas } \\
\text { Pemilu Desa Pemilihan Presiden } \\
\text { dan Wakil Presiden Legislatif }\end{array}$ & Tugino, SH. MH \\
\hline 4. & $20.00-20.30$ & $\begin{array}{l}\text { Materi 2 SDM (Sumber Daya } \\
\text { Manusia) }\end{array}$ & Harini, SE,MM \\
\hline 5. & $20.30-21.00$ & $\begin{array}{l}\text { Materi 3 Pengawasan Partisipatif } \\
\text { Dr.Slamet, S.Pd., } \\
\text { M.Pd., M.Si. }\end{array}$ \\
\hline 6. & $21.00-21.30$ & Istirahat atau Penutup & \\
\hline
\end{tabular}

\section{Hari Keempat}

\begin{tabular}{|c|c|l|c|}
\hline No & Waktu & \multicolumn{1}{|c|}{ Kegiatan } & Penyaji \\
\hline$(1)$ & $(2)$ & \multicolumn{1}{|c|}{$(3)$} & T) \\
\hline 1. & $18.00-19.00$ & Sambutan Ketua DPM & Camat Mranggem \\
\hline 2. & $19.00-19.30$ & Sambutan Pemangku Wilayah & Tugino, SH. MH \\
\hline 3. & $19.30-20.00$ & $\begin{array}{l}\text { Materi 1 Penyuluhan Dan } \\
\text { Bimbingan Teknis Pengawas } \\
\text { Pemilu Desa Pemilihan Bupati } \\
\text { dan wakil Bupati Demak }\end{array}$ & \\
\hline
\end{tabular}




\begin{tabular}{|c|c|l|l|}
\hline$(1)$ & \multicolumn{1}{|c|}{$(2)$} & \multicolumn{1}{|c|}{$(3)$} & \multicolumn{1}{|c|}{$(4)$} \\
\hline 4. & $20.00-20.30$ & $\begin{array}{l}\text { Materi 2 SDM (Sumber Daya } \\
\text { Manusia) }\end{array}$ & Harini,SE,MM \\
\hline 5. & $20.30-21.00$ & Materi 3 Pengawasan Partisipatif & $\begin{array}{l}\text { Dr. Slamet, S.Pd., } \\
\text { M.Pd., M.Si. }\end{array}$ \\
\hline 6. & $21.00-21.30$ & Istirahat atau Penutup & \\
\hline
\end{tabular}

\section{Pembahasan}

Model kegiatan dari pelaksanaan pengabdian pada masyarakat ini adalah memberikan penyuluhan dan bimbingan teknis atau Bintek tentang pengawasan dalam pemilihan kepala daerah sebagai salah satu langkah kegiatan untuk meningkatkan profesionalitas. Kepentingan tersebut dilaksanakan dengan 3 (tiga) tahapan, yaitu: 1) persiapan; 2) pelaksanaan; dan 3) evaluasi.

1. Persiapan

Tahapan ini meliputi persiapan yang akan jadi pengawas pemilu desa untuk pemilihan Bupati dan wakil Bupati Demak melalui metode ceramah dengan para calon Pengawas Pemilu Desa (PPD) di tingkat desa agar nanti dalam menerapan peraturan perundang-undangan dapat berjalan dengan kepastian hukum atau perundang-undangan Pemilu yang berlaku.

2. Pelaksanaan

Tahapan pelaksanaan penyuluhan dilakukan dalam 4 (empat) tahap dan peserta dibatasi 5 (lima) peserta dari 20 peserta. Hal ini dilakukan terkait dengan pandemic Covic-19, dalam pelaksnaan ini peserta difokuskan membahas kajian UndangUndang Pemilu, sebab undang-undang/hukum pada khalayak umum telah mengetahuinya namun karena undang-undang/hukum Pemilu adalah khusus, maka perlu diadakan pemahaman tentang Pemilu dan dasar aturannya yaitu UndangUndang Pemilu Nomor 10 Tahun 2016, sehingga hasil yang diharapkan setelah penyuluhan dilaksanakan peserta dapat memahami dan menerapkan aturan-aturan tentang pemilihan Bupati dan Wakil Bupati Kabupaten Demak.

3. Evaluasi 
Tahapan evaluasi meliputi evaluasi terhadap proses dan hasil penyuluhan. Evaluasi dilaksanakan dengan menggunakan instrumen/angket yang di isi oleh responden sebagai peserta bimbingan teknis terhadap pemahaman materi yang telah diberikan.

\section{SIMPULAN}

Bertitik tolak dari pelaksanaan kegiatan pengabdian pada masyarakat yang telah diuraikan sebelumnya, maka dapat dberikan beberapa simpulan berikut.

1. Peserta calon Pengawas Pemilu Desa (PPD) dalam menjalankan tugas pengawasan Pemilu harus benar-benar memiliki komitmen untuk dapat mewujudkan terselenggaranya pemilihan Kepala daerah/Bupati dan wakilnya secara demokrasi, langsung, umum, bebas, rahasia, jujur, adil dan ber-kwalitas, serta dilaksanakannya peraturan perundang-undangan tentang pemilihan kepala daerah secara menyeluruh.

2. Dalam rangka perwujudan dan penegakan integritas penyelenggaraan, transparansi penyelenggaraan, dan akuntabilitas hasil pemilihan kepala daerah serta guna mensosialisasikan pendidikan politik bagi masyarakat, maka dalam pelaksanaan Pemilu harus dilakukan secara bertanggungjawab.

3. Para calon Pengawas Pemilu dalam melakukan pengawasan tahapan kampanye Pemilu Kepala Daerah berpedoman pada azas: mandiri, jujur, adil, dan kepastian hukum, tertib untuk kepentingan umum, keterbukaan profesionalitas, efisiensi, dan memiliki keefektifan dalam pengawasannya.

Sebagai akhir dari laporan ini disampaikan beberapa saran yangterkait dengan pelaksanaan pengabdian pada masyarakat yang akan datang adalah adanya keberlanjutan dari penyuluhan ini agar para calon pengawas Pemilu Desa benar-benar ada koordinasi dan menjadikan motivasi dalam rangka Pemilu yang berkwalitas sehingga akan tercipta suasana demokrasi berdasarkan Pancasila yang jujur dan adil, tertib dan sukses dalam pesta demokrasi di Kabupaten Demak khususnya dan wilayah di Indonesia pada umumnya.

\section{DAFTAR PUSTAKA}

Undang-Undang Dasar Negara Republik Indonesia Tahun 1945.

Undang-Undang Nomor 7 tahun 2017 tentang Pemilihan Umum. 
Penyuluhan dan Bimbingan Teknik Pengawas TPS Kampanye Pemilu Tingkat Desa dalam Pemilihan Bupati dan Wakil Bupati Tahun 2020 se-Kecamatan

Undang-Undang Nomor 10 Tahun 2016 tentang Pemilihan Gubenur dan Wakil Gubernur dan Bupati dan Wakil Bupati.

PKPU Nomor 11 Tahun 2018 tentang Penyusunan Pemilihan di Dalam Negeri dalam Penyelenggara Pemilihan Umum.

PKPU Nomor 23 Tahun 2017 tentang Kampanye.

Peraturan Bawaslu Nomor 21 Tahun 2018 tentang Penyelenggara Pemilihan Umum.

PKPU Nomor 16 Tahun 2018 tentang Pengawasan Pencalonan Perseorangan Pesertra Pemilihan Gubernur Anggota Dewan Perwakilan Daerah.

Perbawaslu Nomor 23 Tahun 2018 tentang Pengawasan Pencalonan Peserta Pemilihan Umum Anggota DPR, DPRD, dan DPD.

Perbawaslu Nomor 21 Tahun 2018 tentang Pengawasan Penyelenggara Pemilihan Umum.

Perbawaslu Nomor 24 Tahun 2018 tentang Pengawasan Pemutakhiran Data dan Penyusunan Daftar Pemilih Dalam Pemilihan Umum.

Perbawaslu Badan Pengawas Pemilihan Umum Republik Indonesia Nomor 28 Tahun 2018 tentang Pengawasan Kampanye Pemilihan Umum. 
MANGGALI - https://doi.org/10.31331/manggali.v1i1.1544/

Tugino, Harini, Slamet 